\title{
Identifying the influence of urbanization on soil organic matter content and pH from soil magnetic characteristics
}

\author{
YANG Han ${ }^{1,2}$, XIONG Heigang ${ }^{3}$, CHEN Xuegang ${ }^{2}$, WANG Yaqi ${ }^{2}$, ZHANG Fang ${ }^{1}$ \\ ${ }^{1}$ College of Resource and Environment Sciences, Xinjiang University, Urumqi 830046, China; \\ ${ }^{2}$ College of Geographical Science and Tourism, Xinjiang Normal University, Urumqi 830054, China; \\ ${ }^{3}$ College of Applied Arts and Science of Beijing Union University, Beijing 100191, China
}

\begin{abstract}
Soil magnetic characteristics are correlated with soil pH and organic matter content. Analyzing soil magnetic characteristics, organic matter content and $\mathrm{pH}$ can indirectly evaluate soil pollution caused by human activities. This study analyzed the soil magnetic characteristics, organic matter content and $\mathrm{pH}$ in surface soil samples from different land use types in Shihezi city, a newly and rapidly developing oasis city in Xinjiang of China. The aims of this study were to explore the possible relationships among the soil magnetic parameters and thereby improve the understanding of influence of urbanization on soil properties. Eighty surface soil samples at the depth of $0-10 \mathrm{~cm}$ were collected from 29 July to 4 August 2013. The results showed that the magnetic minerals in surface soil were dominated by ferromagnetic minerals. Spatially, the magnetic susceptibility $(X\llcorner F)$, anhysteretic remanent magnetization susceptibility ( $\left.\chi_{A R M}\right)$, saturation isothermal remanent magnetization ( $\left.S I R M\right)$ and "soft" isothermal remanent magnetization (SOFT) were found to be most dominant in the new northern urban area $B(N-B)$, followed by built-up areas $(U)$, suburban agricultural land $(F)$, and then the new northern urban area $A(N-A)$. The values of $X \mathrm{LF}, X_{\mathrm{ARM}}, \mathrm{SIRM}$ and SOFT were higher in the areas with high intensities of human activities and around the main roads. Meanwhile, the property "hard" isothermal remanent magnetization (HIRM) followed the order of $\mathrm{U}>\mathrm{N}-\mathrm{B}>\mathrm{F}>\mathrm{N}-\mathrm{A}$. Built-up areas had an average $\mathrm{pH}$ value of 7.93 , which was much higher than that in the new northern urban areas as well as in suburban agricultural land, due to the increased urban pollutant emissions. The average value of soil organic matter content in the whole study area was $34.69 \mathrm{~g} / \mathrm{kg}$, and the values in the new northern urban areas were much higher than those in the suburban agricultural land and built-up areas. For suburban agricultural land, soil organic matter content was significantly negatively correlated with $X \mathrm{LF}$, and had no correlation with other magnetic parameters, since the soil was frequently ploughed. In the new northern urban areas (N-A and N-B), there were significant positive correlations of soil organic matter contents with XARM, SIRM, SOFT and HIRM, because natural grasslands were not frequently turned over. For the built-up areas, soil organic matter contents were significantly positively correlated with $X_{\mathrm{LF}}, X_{\mathrm{ARM}}, \mathrm{SIRM}$ and SOFT, but not significantly correlated with frequency-dependent susceptibility ( $X_{\mathrm{FD}}$, expressed as a percentage) and HIRM, because the soil was not frequently turned over or influenced by human activities. The results showed that soil magnetic characteristics are related to the soil turnover time.
\end{abstract}

Keywords: environmental magnetism; surface soil; pH; soil organic matter content

Citation: YANG Han, XIONG Heigang, CHEN Xuegang, WANG Yaqi, ZHANG Fang. 2015. Identifying the influence of urbanization on soil organic matter content and pH from soil magnetic characteristics. Journal of Arid Land, 7(6): 820-830. doi: 10.1007/s40333-015-0052-x

Urbanization and urban development have significant influences on environment. Associated with such de- velopment, natural resource consumption and environmental degradation become more and more serious

\footnotetext{
"Corresponding author: XIONG Heigang (E-mail: heigang@buu.edu.cn) Received 2015-01-12; revised 2015-04-13; accepted 2015-04-24

(C) Xinjiang Institute of Ecology and Geography, Chinese Academy of Sciences, Science Press and Springer-Verlag Berlin Heidelberg 2015
} 
(Jorgenson and Rice, 2005; Elliott et al., 2014; Si et al., 2014). Furthermore, urbanization and industrialization are responsible for producing large amount of pollutants, resulting in serious problem to the natural environments, including the pedosphere (Burgess, 2008; Kong et al., 2012; Elmqvist et al., 2013). The ecological environment of urban soil is closely related to human health, and is thus a hotpoint both in the scientific communities and among the general publics (Wei and Yang, 2010; Chabukdhara and Nema, 2013; Li et al., 2013).

Previous studies showed that anthropogenic pollutants in the soil have different magnetic properties to soil natural material samples and can change the presence of other magnetic materials in the soil (Kapička et al., 1999, 2000; Wang et al., 2014). The magnetic properties, organic matter content and $\mathrm{pH}$ of soil are closely related to the soil physical-chemical properties (Huang et al., 2008; Murdock et al., 2013; Shen et al., 2013). Soil magnetic characteristics are correlated with heavy metal content, $\mathrm{pH}$, organic matter content and polycyclic aromatic hydrocarbon content, which can change the magnetic properties of the soil, improve the transmission and absorption of soil nutrients, and influence the metallic elements and pollutants that exist in the soil (Huang et al., 2008). Magnetic characteristics also affect soil biological efficiency and reflect soil pollution to some extent (Zeng et al., 2011; Wang et al., 2013). Thus, analyzing soil magnetic characteristics, organic matter content and $\mathrm{pH}$ is important to indirectly evaluate soil pollution caused by human activities.

Environmental magnetism has been widely used to delineate a serious of ecological and environmental pollution types, as well as to reconstruct pollution histories and conduct analyses of pollutant sources (Gautam et al., 2005; Rosowiecka and Nawrocki, 2010; Yang et al., 2011). Previous studies have focused mainly on the correlation between soil magnetic parameters and the quantity of heavy metal pollution (Wang, 2013; Xia et al., 2014) or the soil physical-chemical properties in suburban agricultural land. However, little attention has been paid to the soil magnetic characteristics and physical-chemical properties of urban soil.

The objectives of this study were to survey the soil magnetic characteristics, organic matter content and $\mathrm{pH}$ in the built-up areas, suburban agricultural land and a new town site in Shihezi city of Xinjiang, and to develop a new method for identifying the influence of urbanization based on soil magnetic characteristics.

\section{Study area}

Shihezi city $\left(84^{\circ} 58^{\prime}-86^{\circ} 24^{\prime} \mathrm{E}, 43^{\circ} 26^{\prime}-45^{\circ} 20^{\prime} \mathrm{N}\right.$; Fig. 1), located in the northern region of central Tianshan Mountains and in the south of Junggar Basin, is 150 $\mathrm{km}$ away from Urumqi, the capital of Xinjiang Uygur autonomous region. With its flat terrain, the altitudes range from 300 to $500 \mathrm{~m}$. The area is characterized by a temperate continental climate, with an annual average temperature of $7.5^{\circ} \mathrm{C}$, an average precipitation of $180-270 \mathrm{~mm}$ and an average evaporation of $1,000-1,500 \mathrm{~mm}$.

Shihezi is a newly and rapidly developed oasis city in recent 55 years and is the central part of the northern economic belt of Tianshan Mountains. Land use survey data showed that the size of the administrative area of Shihezi city was $68.57 \mathrm{~km}^{2}$ by the end of 2009, with $11.39 \mathrm{~km}^{2}$ occupied by townships, villages and industries. Currently, the city has a population of approximately $0.42 \times 10^{6}$. The industrial structure has shifted from the textiles industrial and agriculture to the chemical and energy productions. As a result, environmental pollution is becoming an increasingly serious issue.

\section{Materials and methods}

\subsection{Sampling sites distribution and sampling methods}

The sampling sites with different land use types covered urban areas and neighboring farmland (Fig. 1). We classified the sampling sites into four sub-regions according to the land function and establishment time: built-up areas (U); suburban agricultural land, including arable land in the suburbs and around industrial areas $(\mathrm{F})$; a new northern urban area $\mathrm{A}(\mathrm{N}-\mathrm{A})$; and a new northern urban area $B(N-B)$. Located south of the National Highway 312, the land functions in $\mathrm{U}$ include transportation, education and culture, social services, and industries such as food processing, 


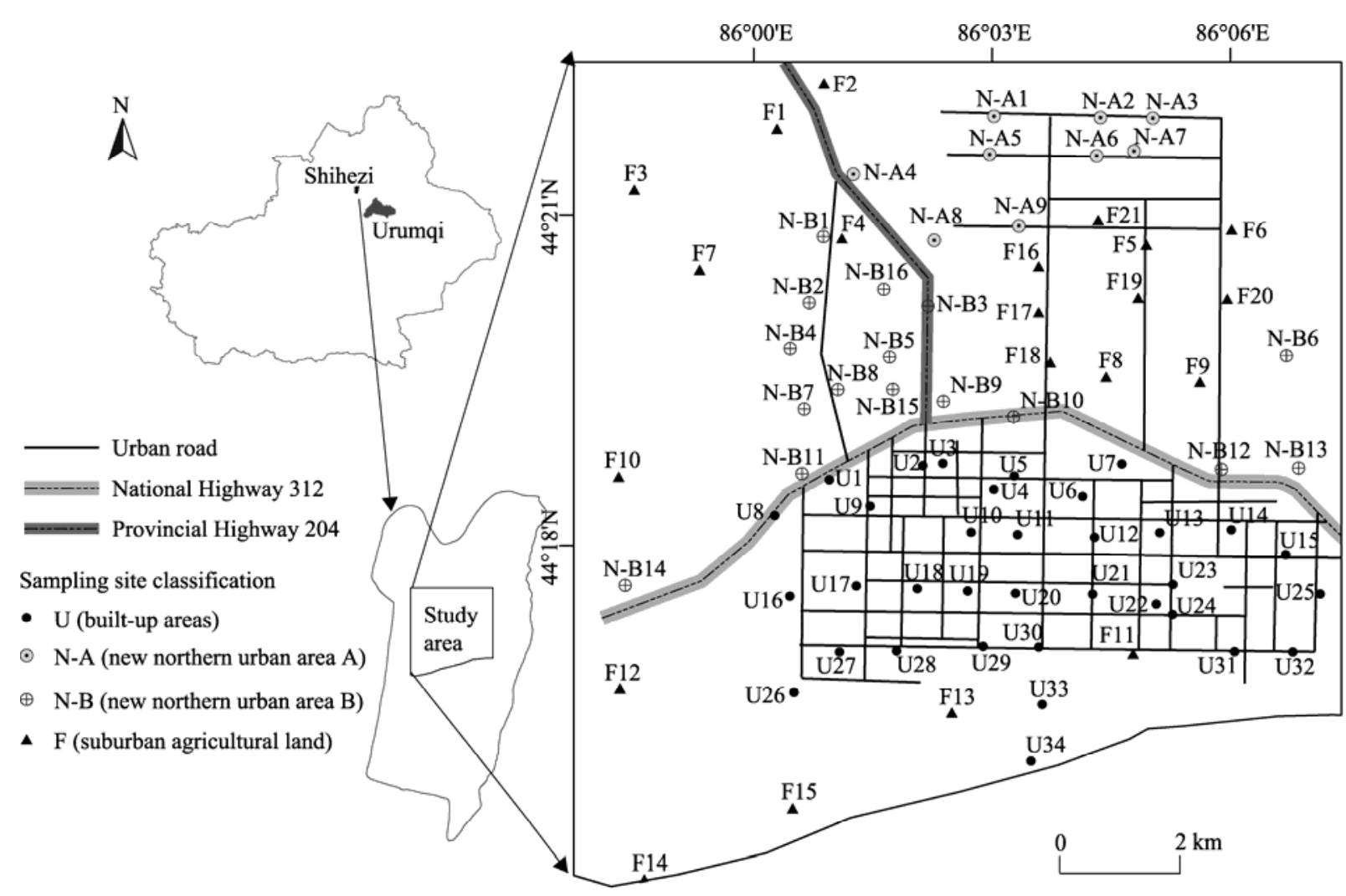

Fig. 1 Locations of the study area and sampling sites

cotton spinning and building materials production.Founded in 2003, N-A was originally developed with heavy chemical industry, with a planned area of $31.2 \mathrm{~km}^{2}$ for chloralkali industry, coal industry, and petroleum and natural gas chemical engineering. N-B is an economic and technological development zone, located north of National Highway 312 and south of Provincial Highway 204 (Yang et al., 2014). We chose the sampling sites based on the uniformity of spatial distribution of soil, taking the soil distribution and accessibility into consideration. Compared with $\mathrm{F}$, there were more pollutant sources in U, N-A and N-B. The sampling sites were taken at the resolution of 1 $\mathrm{km} \times 1 \mathrm{~km}$ in $\mathrm{U}, \mathrm{N}-\mathrm{A}$ and $\mathrm{N}-\mathrm{B}$, and $2 \mathrm{~km} \times 2 \mathrm{~km}$ in $\mathrm{F}$ because of the lower amount of pollutant sources.

From 29 July to 4 August 2013, 80 soil samples (34 in U, 9 in N-A, 16 in N-B and 21 in F) were collected from the soil depth of $0-10 \mathrm{~cm}$. Each soil sample was obtained by mixing five to six subsamples within $10 \mathrm{~m}^{2}$ with a weight of $0.5 \mathrm{~kg}$, put in a polyethylene bag and numbered accordingly. Each sampling site was positioned by GPS, with surrounding conditions recorded.

\subsection{Experimental methods and data analysis}

After natural drying for two weeks, the soil samples were sieved through a 1-mm nylon sieve to remove fallen leaves, plant roots and stubble. After weighing, they were packed in plastic film respectively and put into a special magnetic sample box $\left(10 \mathrm{~cm}^{3}\right.$ in volume $)$ for testing.

Low- and high-field magnetic susceptibility $\chi_{\mathrm{LF}}$ and $\chi_{\mathrm{HF}}$, respectively) were obtained using a dual-frequency (470 and 4,700 Hz, respectively) susceptibility meter (MS2-B, Bartington Instruments, British), allowing the frequency-dependent susceptibility $\left(\chi_{\mathrm{FD}}\right.$; in \%) to be calculated $\left(\chi_{\mathrm{FD}}=\left[\left(\chi_{\mathrm{LF}}-\chi_{\mathrm{HF}}\right) / \chi_{\mathrm{LF}}\right] \times 100\right)$. The isothermal remanent magnetization (IRM) was measured using an ASC IM-10 pulse magnetizing apparatus and a Molspin spinner magnetometer. First, an ASC IM-10 pulse magnetizing apparatus was applied with the field strengths of 20,60, 100, 300 and $1,000 \mathrm{mT}$ sequentially, and then a spinner magnetometer was used to measure the corresponding IRM, with the IRM under a field strength of $1,000 \mathrm{mT}$ to be de- 
fined as saturation IRM (SIRM). The IRMs under the reversed magnetic fields of $-20 \quad\left(\mathrm{IRM}_{-20}\right),-60$ $\left(\right.$ IRM-60 $\left._{-6}\right),-100\left(\right.$ IRM $\left._{-100}\right)$ and $-300\left(\right.$ IRM $\left._{-300}\right) \mathrm{mT}$ were also measured. The magnetic parameters were measured at the Xinjiang Laboratory of Lake Environments and Resources in Arid Zones, Xinjiang Normal University. Anhysteretic remanent magnetization (ARM) was induced with an alternating demagnetization instrument (2G-719ARM, USA) and Minispin spinner magnetometer (2G-719ARM, USA); and the hysteresis loop and hysteresis parameters (saturation magnetization $M_{\mathrm{s}}$, saturation remanent magnetization $M_{\mathrm{rs}}$, coercive force $B_{\mathrm{c}}$ and remanent coercivity $B_{\text {cr }}$ ) were determined with a Micromag3900 (Princeton Measurements Corp., USA). The hysteresis loop and hysteresis parameters were measured in the Paleo Magnetism Laboratory of Institute of Geology and Geophysics, Chinese Academy of Sciences. The "hard" and "soft" IRMs (referred to as HIRM and SOFT, respectively) were calculated as $\left(\mathrm{SIRM}+\mathrm{IRM}_{-300}\right) / 2$ and $\left(\mathrm{SIRM}_{+} \mathrm{IRM}_{-20}\right) / 2$, respectively. The detailed discussion of the physical significance of magnetic parameters can be found in the studies of Ďurža (1999) and Lourenço et al. (2012). Soil pH was measured with Mettler G20 potentiometric titration after calcium chloride extraction, deionized water using a 1:5 (w:v) of soil:solution ratio. Soil organic matter content was measured using the external heating method of potassium dichromate. The measurements of soil $\mathrm{pH}$ and organic matter content were car- ried out at the Central Laboratory, Xinjiang Institute of Ecology and Geography, Chinese Academy of Sciences.

Statistical analyses were carried out with Microsoft Excel 2013 and SPSS 19.0, while the maps were drawn and the computation was performed using ArcGIS 10.0.

\section{Results and discussion}

\subsection{Spatial distribution of soil magnetic charac- teristics}

The concentration of soil magnetic minerals in a sample can be deduced from the $\chi_{\mathrm{LF}}$. At room temperature, $\chi_{\text {LF }}$ mainly reflects the content of soil ferromagnetic minerals (Evans and Heller, 2003). As a whole, the $\chi_{\text {LF }}$ values in the surface soil of the study area were not high, averaging $89.9 \times 10^{-8} \mathrm{~m}^{3} / \mathrm{kg}$ (Table 1). However, the range of variation was greater and the maximum value was 20 times the minimum value. The former, located in N-B3 was $415.1 \times 10^{-8} \mathrm{~m}^{3} / \mathrm{kg}$; and the latter, in F2, was $20.0 \times 10^{-8} \mathrm{~m}^{3} / \mathrm{kg}$ (Fig. 2a). Among the different sub-regions, the largest average value was found in N-B $\left(114.8 \times 10^{-8} \mathrm{~m}^{3} / \mathrm{kg}\right)$, while the smallest was in N-A $\left(69.2 \times 10^{-8} \mathrm{~m}^{3} / \mathrm{kg}\right)$. The mean $\chi_{\mathrm{LF}}$ value $\left(89.2 \times 10^{-8} \mathrm{~m}^{3} / \mathrm{kg}\right)$ in $\mathrm{U}$ was equal to the overall level of $\chi_{\mathrm{LF}}$ in Shihezi, while the mean $\chi_{\mathrm{LF}}$ value $\left(80.5 \times 10^{-8}\right.$ $\mathrm{m}^{3} / \mathrm{kg}$ ) in $\mathrm{F}$ was below the average value. The concentration of ferromagnetic minerals was largest in N-B, followed by U, F, and then N-A. Grasslands existed in

Table 1 Summary statistics (variation range and mean value) of soil magnetic parameters, organic matter content and $\mathrm{pH}$ values in surface soil

\begin{tabular}{cccccc}
\hline Parameter & $\begin{array}{c}\text { Whole study area } \\
(n=80)\end{array}$ & Built-up areas $(n=34)$ & $\begin{array}{c}\text { Suburban agricultural } \\
\text { land }(n=21)\end{array}$ & $\begin{array}{c}\text { New northern urban } \\
\text { area A }(n=9)\end{array}$ & $\begin{array}{c}\text { New northern urban } \\
\text { area B }(n=16)\end{array}$ \\
\hline$\chi_{\text {LF }}\left(10^{-8} \mathrm{~m}^{3} / \mathrm{kg}\right)$ & $20.0-415.1(89.9)$ & $37.9-323.7(89.2)$ & $20.0-395.3(80.5)$ & $26.1-227.1(69.2)$ & $24.1-415.1(114.8)$ \\
$\chi_{\mathrm{FD}}(\%)$ & $0.2-9.1(3.4)$ & $0.7-8.2(2.9)$ & $0.2-9.1(3.2)$ & $0.4-8.0(3.5)$ & $0.3-8.5(4.4)$ \\
$\chi_{\text {ARM }}\left(10^{-8} \mathrm{~m}^{3} / \mathrm{kg}\right)$ & $66.9-1,972.8(93.6)$ & $40.3-287.0(90.08)$ & $17.5-267.2(80.0)$ & $31.4-199.8(67.1)$ & $24.7-451.4(132.8)$ \\
SIRM $\left(10^{-5} \mathrm{~A} \mathrm{~m}^{2} / \mathrm{kg}\right)$ & $495.5-12,296.2$ & $618.4-9,256.1$ & $495.5-10,341.4$ & $654.6-4,702.4$ & $505.6-12,296.2$ \\
& $(2,656.3)$ & $(2,867.6)$ & $(2,259.1)$ & $(1,449.8)$ & $(3,382.5)$ \\
SOFT $\left(10^{-5} \mathrm{~A} \mathrm{~m}^{2} / \mathrm{kg}\right)$ & $78.9-4,998.6$ & $182.5-4,217.9$ & $80.7-4,145.7$ & $78.9-2,038.7$ & $189.5-4,998.6$ \\
& $(941.3)$ & $(1,022.3)$ & $(733.7)$ & $(531.2)$ & $(1,331.0)$ \\
HIRM $\left(10^{-5} \mathrm{~A} \mathrm{~m} / \mathrm{kg}\right)$ & $0.3-2,388.8(155.2)$ & $17.7-2,388.8(203.0)$ & $0.3-611.9(123.6)$ & $27.6-386.6(102.6)$ & $8.7-503.4(125.9)$ \\
$\mathrm{SOM}$ content $(\mathrm{g} / \mathrm{kg})$ & $8.1-122.5(34.7)$ & $8.1-75.0(26.7)$ & $10.8-69.9(29.5)$ & $21.5-122.5(48.8)$ & $11.1-94.8(50.3)$ \\
$\mathrm{pH}$ & $7.08-9.09(7.93)$ & $7.62-9.09(8.04)$ & $7.08-8.32(7.85)$ & $7.53-8.07(7.76)$ & $7.48-8.42(7.90)$ \\
\hline
\end{tabular}

Note: Values in the parentheses represent the mean values. $\chi_{\mathrm{LF}}$, low-field magnetic susceptibility; $\chi_{\mathrm{ARM}}$, anhysteretic remanent magnetization susceptibility; SIRM, saturation isothermal remanent magnetization; SOFT, "soft" isothermal remanent magnetization; HIRM, "hard" isothermal remanent magnetization; SOM, soil organic matter. 
$\mathrm{N}-\mathrm{A}$ before the urban development, and quite a low concentration of soil ferromagnetic minerals was found here as a result of low magnetism due to pollution with sulfide from heavy chemical industry. The concentration of soil ferromagnetic minerals was highest in N-B because it is the industry development centre where distributes newly built facilities, a commercial plaza and heavy traffics. F8, F18 and U7, near National Highway 312, had relatively higher values of soil ferromagnetic minerals. Soil magnetic mineral concentrations in the suburbs were lower than those in
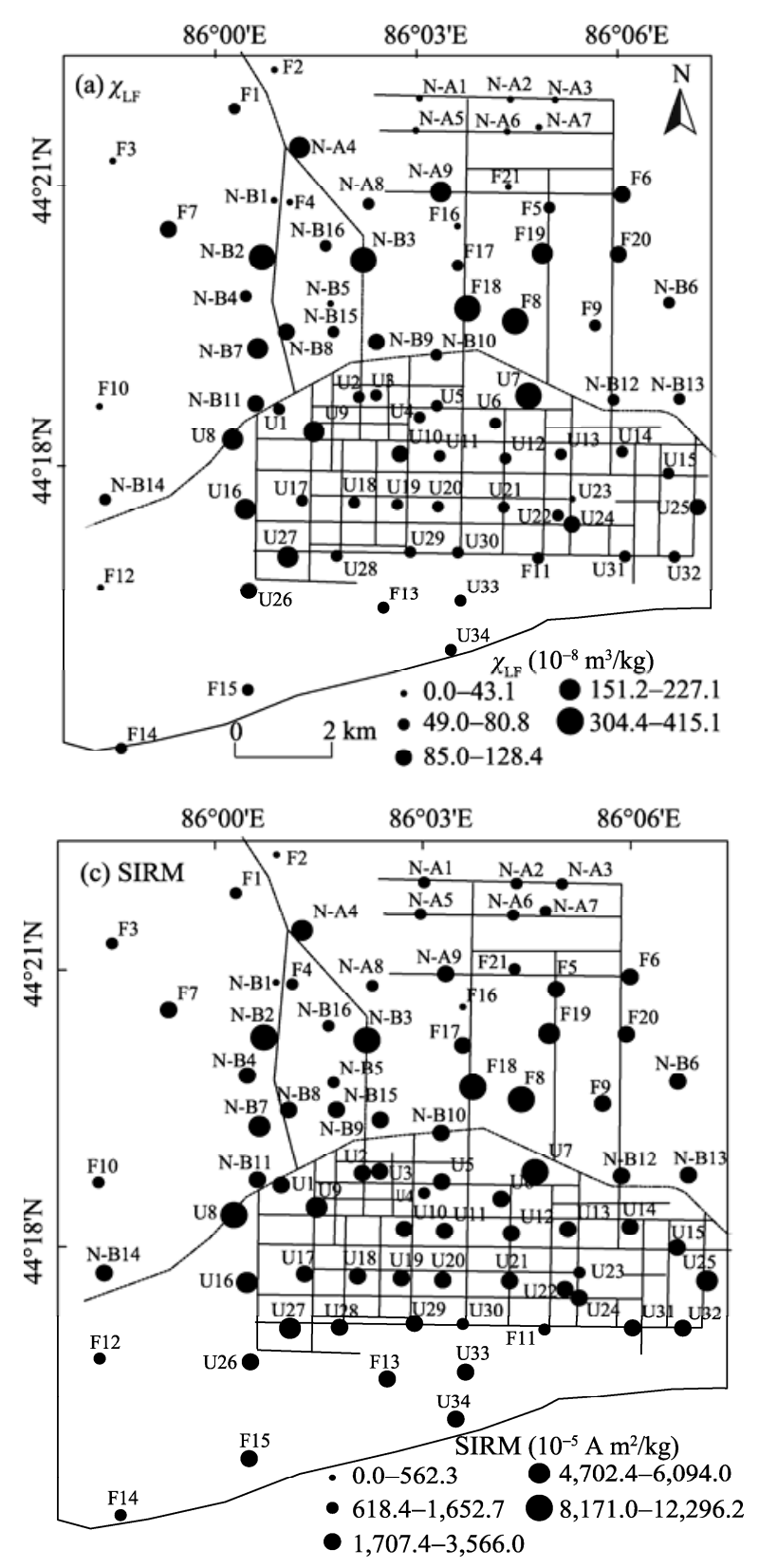

the other areas (except for the area of heavy chemical industry in N-A). From the distribution of $\chi_{\mathrm{LF}}$ we concluded that closer proximity to human activity results in higher $\chi_{\mathrm{LF}}$, which is in agreement with the results of other previous researches (Thompson and Oldfield, 1986; Zheng and Zhang, 2008).

SIRM, $\chi_{\mathrm{ARM}}$, SOFT and HIRM can also reflect the concentrations of soil magnetic minerals. Compared with $\chi_{\mathrm{LF}}$, SIRM mainly reflects the contents of soil ferromagnetic and canted anti-ferromagnetic minerals, and is not influenced by the paramagnetic and
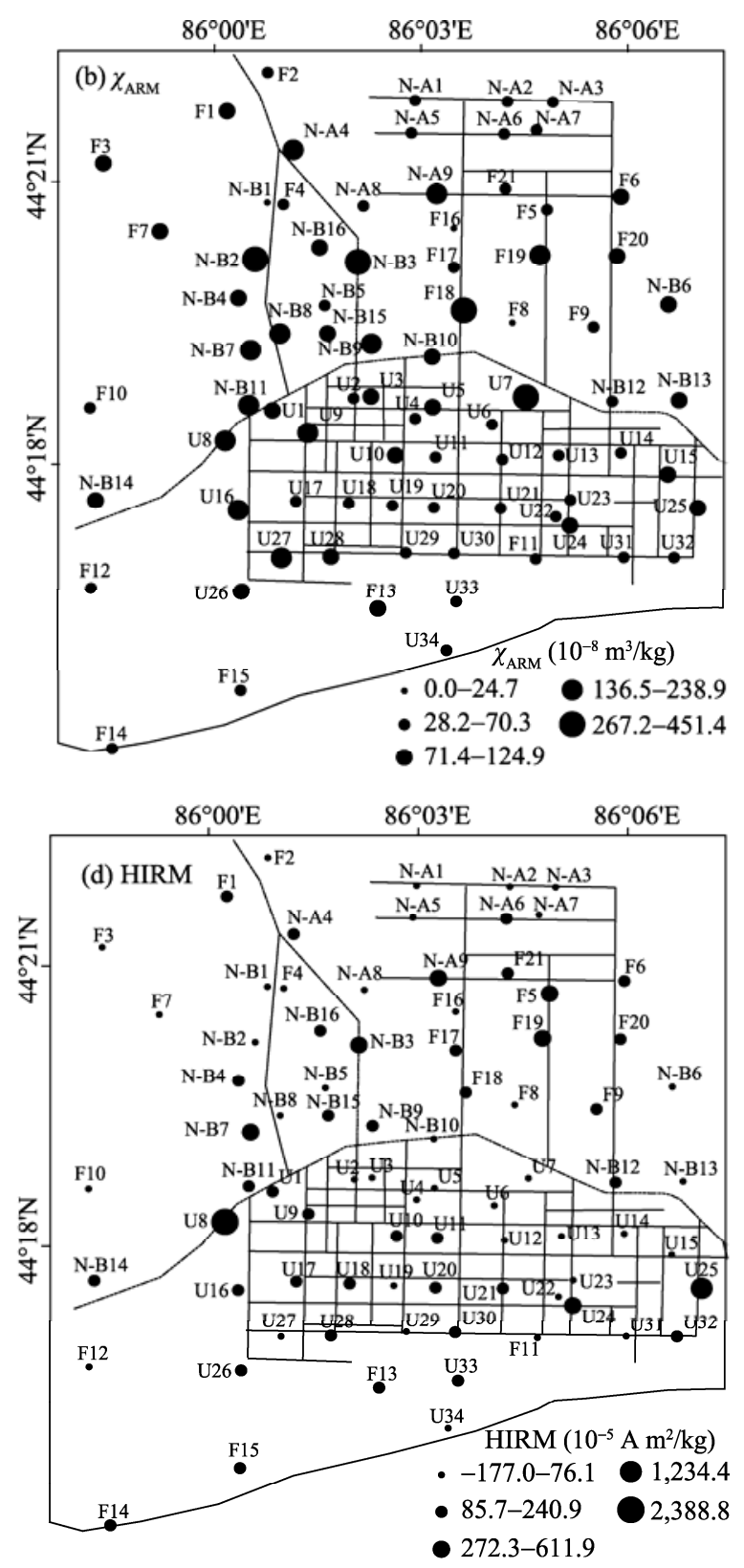

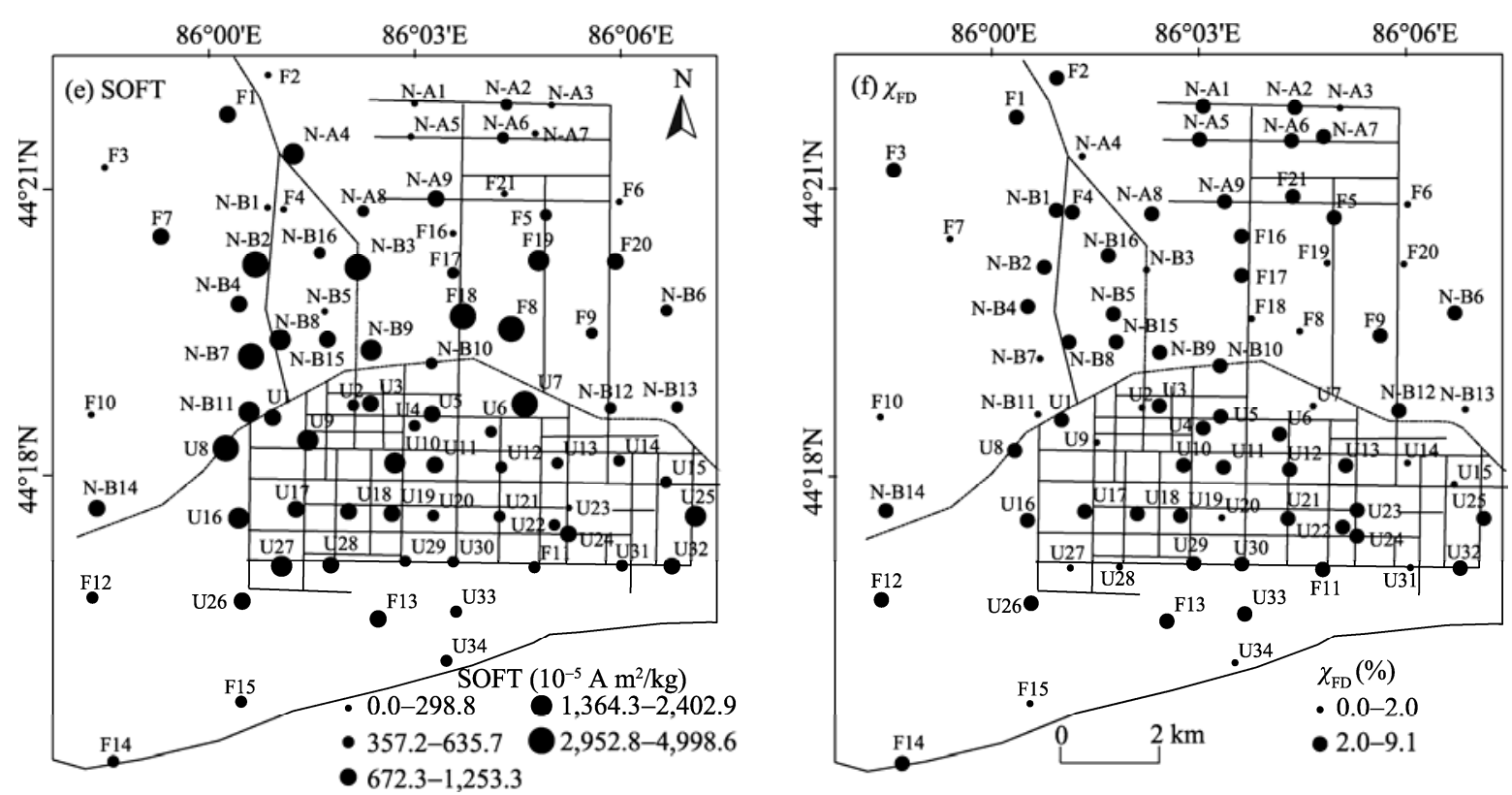

Fig. 2 Spatial distributions of soil magnetic characteristics of surface soils in different sampling sites in the urban area of Shihezi city. $X_{\mathrm{LF}}$, low-field magnetic susceptibility; $X_{\mathrm{ARM}}$, anhysteretic remanent magnetization susceptibility; SIRM, saturation isothermal remanent magnetization; HIRM, "hard" isothermal remanent magnetization; SOFT, "soft" isothermal remanent magnetization; $X_{\mathrm{FD}}$, frequency-dependent susceptibility.

magnetic minerals (Thompson and Oldfield, 1986). The parameter $\chi_{\text {ARM }}$ mainly indicates single domain (SD) and pseudo-single domain (PSD) particle ferromagnetic and canted anti-ferromagnetic minerals (Thompson and Oldfield, 1986). SOFT (IRM acquired at magnetic intensity of $20 \mathrm{mT}$ ) mainly reflects low coercive multi-domain (MD) ferromagnetic minerals. Ferromagnetic minerals basically reach the saturation point at a magnetic intensity of $200-300 \mathrm{mT}$, with no contribution to HIRM. Thus, HIRM (IRM acquired at magnetic intensity of $300 \mathrm{mT}$ ) mainly reflects high coercive canted anti-ferromagnetic minerals (hematite and goethite). The similar distributions of SIRM, $\chi_{\text {ARM }}$ and $\chi_{\mathrm{LF}}$ (Fig. 2) showed that soil ferromagnetic and canted anti-ferromagnetic minerals dominated $\chi_{\mathrm{LF}}$. Moreover, the similar distributions of SOFT and $\chi_{\mathrm{LF}}$ further explained how soil ferromagnetic minerals dominated $\chi_{\mathrm{LF}}$ in the samples. The values of SIRM, $\chi_{\text {ARM }}$ and SOFT were relatively high in N-B2, N-B3, F8, F18 and U7 (Figs. 2b, c and e), indicating that the higher intensities the human activity, the higher the values. Large differences in the distributions of HIRM and $\chi_{\text {LF }}$ (Figs. $2 \mathrm{a}$ and d) showed that the canted anti-ferromagnetic minerals did not dominate the magnetic characteristics in the samples. Besides, HIRM in
U was significantly higher than that in the other areas, which can be used as an effective indicator for evaluating urban pollution caused by human activities.

Soil magnetic parameters of $\chi_{\mathrm{LF}}$, SIRM, $\chi_{\mathrm{ARM}}$, SOFT and HIRM were found to be relatively high on the both sides of the roads (Figs. 2a-e) because the automobile exhaust emissions, factories and major production activities were concentrated in those areas, while they were relatively low in U and N-A. It can be concluded that the differences of spatial distributions of soil magnetic characteristics reflect the pollution status of soil, as the magnetic environment is influenced by human activities with different land use types, timespans and intensities.

$\chi_{\mathrm{FD}}$ is another effective parameter for judging the superpara magnetic (SP) ferromagnetic component (Dearing et al., 1996). For the whole study area, the values of $\chi_{\mathrm{FD}}$ ranged from 0 to $10 \%$ (Fig. $2 \mathrm{f}$ ), suggesting that SP and coarse particles coexisted in the soil samples (Maher, 1998; Dearing, 1999).

It can be concluded that the magnetic minerals in the soil samples of the study area were mainly magnetite. If magnetite is the main magnetic minerals, thus the Dearing and Day plots can be used to judge the size of the magnetic mineral particles (Day et al., 
1977; Dearing et al., 1997), with $\chi_{\mathrm{FD}}$ as the vertical axis and $\chi_{\text {ARM }} / S I R M$ as the projected quantity along the horizontal axis in the Dearing plot (Fig. 3). All sample values fell within the scope of PSD+MD, with a relatively low content of SP particle (Fig. 3a), showing that the magnetic minerals were coarser in the soil samples, being pseudo-single domain and multi-domain granules. Soil samples from different sub-regions were projected in the Day plot, and the samples mainly fell into the PSD scope (Fig. 3b).

\subsection{Spatial distribution of soil acidity}

Soil $\mathrm{pH}$ not only reflects the properties of soil quality, but also influences other soil physical-chemical properties. Soil acidity and alkalinity are mainly influenced by soil formation under different climates, parent materials and vegetations. After a long period of geological and microbiological cycling, a stable pattern of soil acidity and alkalinity in a city has taken shape (Chen et al., 2011). Moreover, soil pH is also influenced by human factors to a great extent. In the study area, the average $\mathrm{pH}$ value in surface soil was 7.93 (slight alkaline), with the range of 7.08-9.09. The smallest $\mathrm{pH}$ value was found in a cotton field of northwest suburb (F1), and the largest value on the lawn of the Yanjing Beer Factory in a southeastern urban area (U31). Soil $\mathrm{pH}$ in $\mathrm{U}$ was higher than that in other three sub-regions, with an average value of

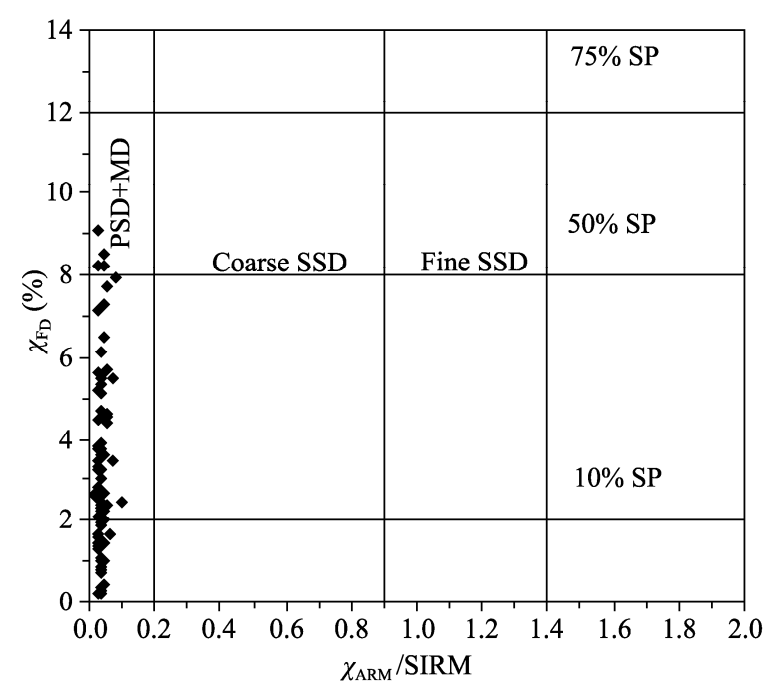

8.04 and a variation of 7.62-9.09. The average soil $\mathrm{pH}$ values in $\mathrm{N}-\mathrm{A}, \mathrm{F}$ and $\mathrm{N}-\mathrm{B}$ were about the same, with the values of $7.75,7.85$ and 7.90 , respectively (Table 1).

Several factors contributed to the relatively high $\mathrm{pH}$ in U. First, this sub-region was established for a longer time, with the land functions of transportation, education and culture, and social services, as well as industrial land for food processing, cotton spinning and building materials production. During the process of urbanization, building wastes, cement and other alkaline mixtures were discharged into the neighboring soil, resulting in high soil $\mathrm{pH}$ value. Second, the increases in $\mathrm{CO}_{2}$ concentrations forced the alkaline materials (e.g. calcium and magnesium) into the soil. Third, weathered concrete also emitted calcium and magnesium into the soil. Moreover, a large amount of carbonate dust was discharged into the urban soil, making it more alkaline than natural soil. This result agrees with those from urban soils in other cities (De Kimpe and Morel, 2000; Tu et al., 2005). It can be seen from Fig. 4, soil $\mathrm{pH}$ was relatively high in the central urban area (U), but it was lower in U9 (a lawn in the residential quarter; $\mathrm{pH} 7.62$ ), U23 (two-story self-built houses; $\mathrm{pH}$ 7.49) and U24 (tree belt; $\mathrm{pH} 7.49$ ) due to the influences from neighboring buildings and household garbage. Moreover, soil pH value in U31

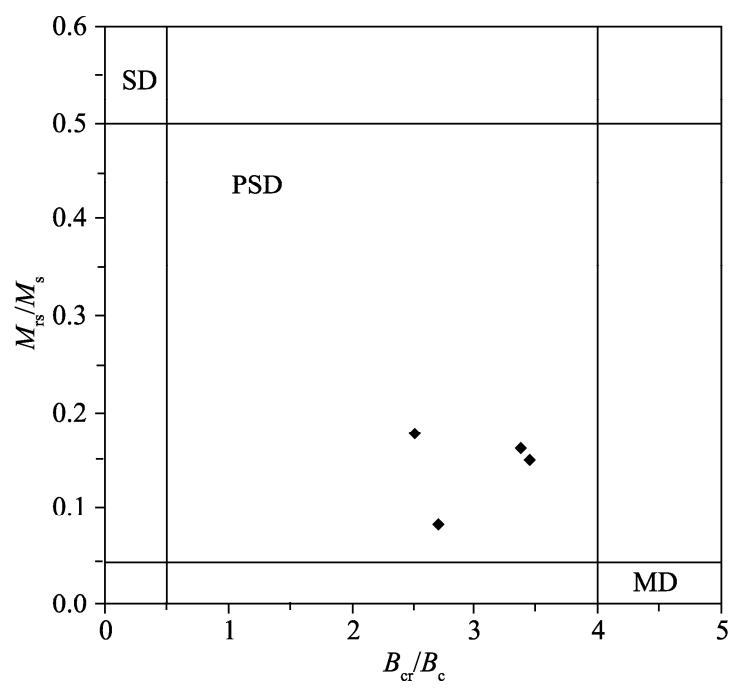

Fig. 3 Dearing plot (left) and day plot (right) of all soil samples. $X_{\mathrm{FD}}$, frequency-dependent susceptibility; PSD, pseudo-single domain; MD, multi-domain; SSD, stable single domain; SP, superpara magnetic; XARM, anhysteretic remanent magnetization susceptibility; SIRM, saturation isothermal remanent magnetization; $M_{\mathrm{s}}$, saturation magnetization; $M_{\mathrm{rs}}$, saturation remanent magnetization; $B_{\mathrm{cr}}$, remanent coercivity; $B_{\mathrm{c}}$, coercive force. 

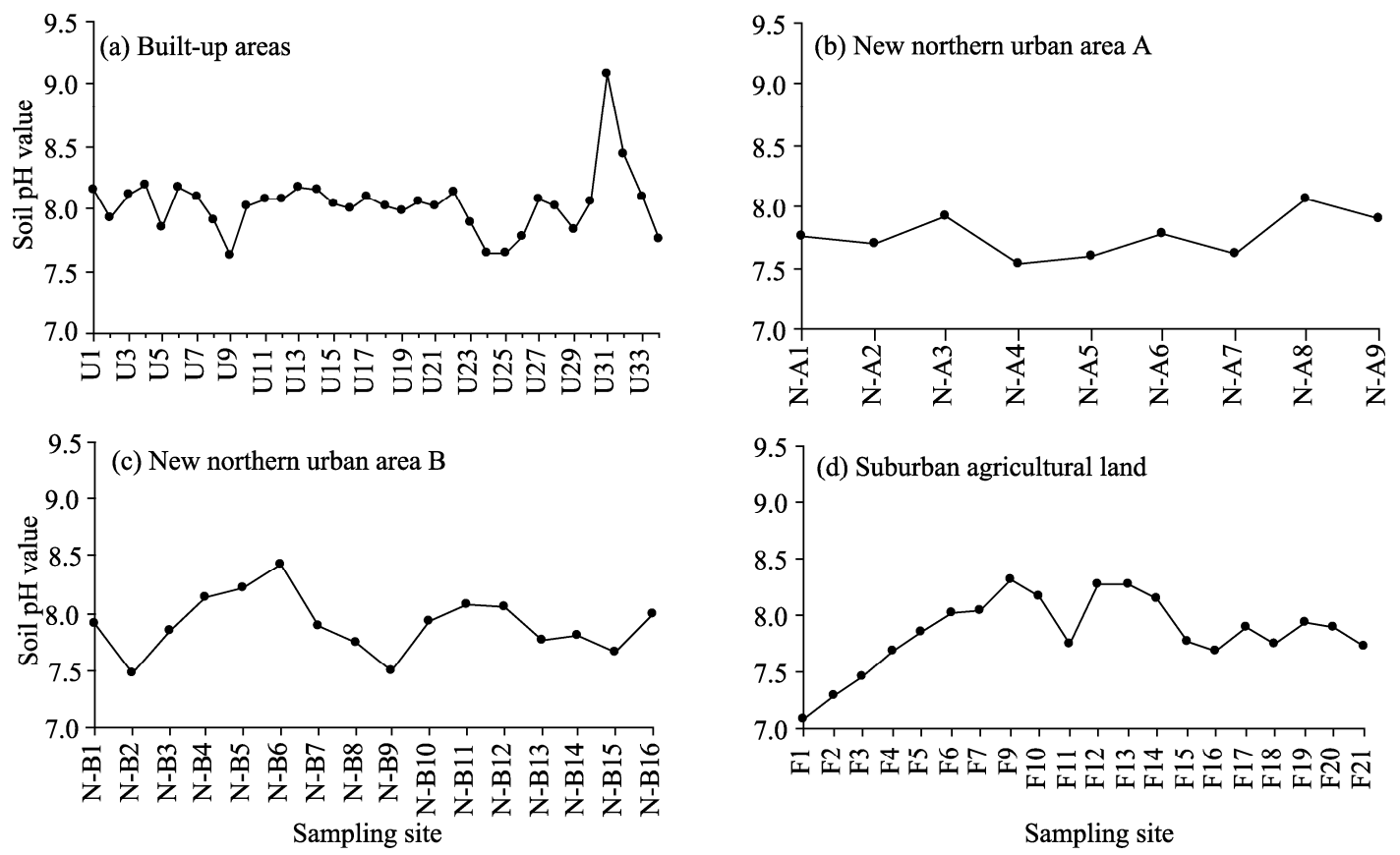

Fig. 4 Soil $\mathrm{pH}$ values in different sampling sites

(Yanjing Beer Factory) was the highest, perhaps related to the beer production. Soil $\mathrm{pH}$ values in N-A, $\mathrm{N}-\mathrm{B}$ and $\mathrm{F}$ were about the same. In these sub-regions, some natural grassland still remains, representing the original soil conditions.

In this study, we found that there was no significant correlation between soil $\mathrm{pH}$ and magnetic parameters, because soil samples were all collected from natural soil and thus the variation of $\mathrm{pH}$ was generally small. The lower variation of soil $\mathrm{pH}$ can be negligible relative to the variation of magnetic parameters.

\subsection{Spatial distribution of soil organic matter content}

As a key component of soil, organic matter directly influences soil physical-chemical properties and biological characteristics, and it is also a composite index reflecting soil nutrition. Soil organic matter plays a key role in transferring nutritional substances, heavy metals and organic toxicants by adsorption and complexation (Reuter and Perdue, 1977; Davis, 1984). Organic matter contents in surface soils of Shihezi city ranged from 8.1 to $122.5 \mathrm{~g} / \mathrm{kg}$, with an average value of $34.7 \mathrm{~g} / \mathrm{kg}$ (Table 1). The minimum value of soil organic matter content was found in U14, and the maximum in N-A9 (Fig. 5). Soil organic matter con- tents varied significantly in the four sub-regions, with the highest in N-B, followed by N-A, F, and then U. Grassland existed in the new northern town before the urban development, and thus the contents of soil organic matter in N-A and N-B were higher, ranging from 11.0 to $122.5 \mathrm{~g} / \mathrm{kg}$. The average value of soil

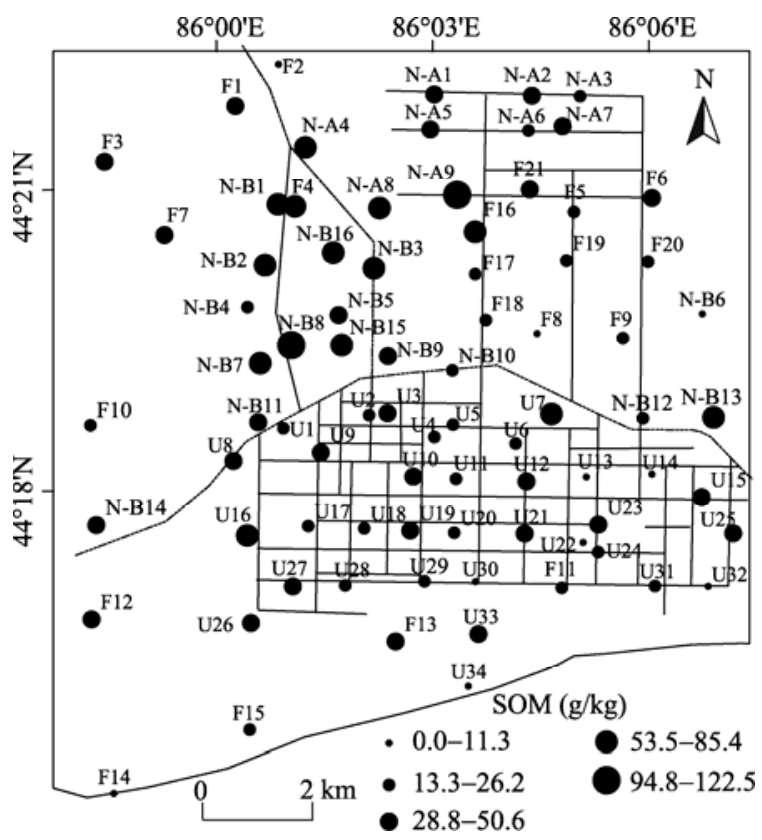

Fig. 5 Distribution of organic matter content for surface soil in Shihezi city 
organic matter content in N-A was $48.8 \mathrm{~g} / \mathrm{kg}$ and in $\mathrm{N}-\mathrm{B}$ was $50.3 \mathrm{~g} / \mathrm{kg}$. Soil organic matter content was lowest in $\mathrm{U}$, with an average of $26.7 \mathrm{~g} / \mathrm{kg}$ and the variation of $8.1-75.0 \mathrm{~g} / \mathrm{kg}$. Soil organic matter content in $\mathrm{F}$ fell between N-A and U, with an average of 29.5 $\mathrm{g} / \mathrm{kg}$ and the variation of $10.8-69.9 \mathrm{~g} / \mathrm{kg}$, twice the average value of Xinjiang farmland (average value of $14.7 \mathrm{~g} / \mathrm{kg}$ and the variation of $5.3-24.2 \mathrm{~g} / \mathrm{kg}$; Jing et al., 2004).

\subsection{Relationship between soil organic matter con- tent and magnetic parameters}

The correlation coefficients of soil organic matter contents with $\chi_{\mathrm{LF}}$ and $\chi_{\mathrm{ARM}}$ were 0.411 and 0.436 $(P<0.01)$, respectively (Table 2$)$. Moreover, the correlation coefficients between soil organic matter content and SIRM, and between soil organic matter content and SOFT, were 0.285 and $0.337(P<0.05)$, respectively. No significant correlation was found between the other soil magnetic parameters and organic matter content. These results indicated an extremely significant correlation among soil organic matter content and ferromagnetic mineral particles, a significant correlation between soil organic matter content and low coercive MD ferromagnetic mineral particles, and no correlation between soil organic matter content and high coercive canted anti-ferromagnetic minerals (hematite and goethite) as well as magnetic particle size in the study area.

As the main pollutant sources varied from region to region, so did the Pearson correlation coefficient between soil organic matter content and magnetic parameters. The sources of soil organic matter can be divided into natural sources and human sources. Located on the Manas alluvial plain, the natural sources of soil organic matter for the above three functional areas were very similar, so the difference existed in the man-made sources. In $U$, soil organic matter con- tents had significant positive correlations with $\chi_{\mathrm{LF}}$, $\chi_{\mathrm{ARM}}, \mathrm{SIRM}$ and SOFT, but no correlation with $\chi_{\mathrm{FD}}$ and HIRM. The above-mentioned correlations showed that, in $\mathrm{U}$, soil organic matter contents were significantly correlated with ferromagnetic mineral particles and low coercive MD ferromagnetic mineral particles, but not correlated with high coercive canted anti-ferromagnetic minerals (hematite and goethite) as well as magnetic particle size, from the perspective of the physical significance of the magnetic parameters.

In N-A, soil organic matter contents were significantly positively correlated with $\chi_{\mathrm{LF}}, \chi_{\mathrm{ARM}}, \mathrm{SIRM}$, SOFT and HIRM $(P<0.01$ or $P<0.05)$, but had no correlation with $\chi_{\mathrm{FD}}$. The correlation results in N-B were similar to those in N-A. These results showed that, in N-A and N-B, there were significant correlations of soil organic matter contents with ferromagnetic mineral particles, low coercive MD ferromagnetic mineral particles, and high coercive canted anti-ferromagnetic minerals (hematite and goethite), while there was no correlation of soil organic matter contents with magnetic particles.

In $\mathrm{F}$, soil organic matter content was found to be negatively correlated with $\chi_{\mathrm{FD}}$ but not significantly correlated with other soil magnetic parameters, differentiating from the results in other three sub-regions. Ploughed at a soil depth of $0-30 \mathrm{~cm}$ each year in F, not only is the soil structure in F destroyed, but also the magnetic minerals are turned over, breaking the correlation between soil organic matter content and magnetic parameters.

Based on the analysis of the relationships between soil organic matter contents and magnetic parameters in different sub-regions, we can be concluded that, the more frequently the soil is ploughed, the less correlation there will be between soil organic matter contents and magnetic parameters.

Table 2 Correlations between organic matter content and magnetic parameters in surface soil

\begin{tabular}{|c|c|c|c|c|c|}
\hline Magnetic parameter & Whole study area $(n=80)$ & Built-up areas $(n=34)$ & $\begin{array}{c}\text { Suburban agricultural } \\
\text { land }(n=21)\end{array}$ & $\begin{array}{c}\text { New northern urban } \\
\text { area } \mathrm{A}(n=9)\end{array}$ & $\begin{array}{c}\text { New northern urban } \\
\text { area } \mathrm{B}(n=16)\end{array}$ \\
\hline$\chi_{\mathrm{LF}}\left(10^{-8} \mathrm{~m}^{3} / \mathrm{kg}\right)$ & $0.411^{* *}$ & $0.733^{* *}$ & $-0.365^{*}$ & $0.926^{* *}$ & $0.454^{*}$ \\
\hline$\chi_{\mathrm{FD}}(\%)$ & 0.179 & -0.155 & 0.350 & -0.173 & -0.129 \\
\hline$\chi_{\mathrm{ARM}}\left(10^{-8} \mathrm{~m}^{3} / \mathrm{kg}\right)$ & $0.436^{* *}$ & $0.781^{* *}$ & -0.179 & $0.694^{*}$ & $0.416^{*}$ \\
\hline $\operatorname{SIRM}\left(10^{-5} \mathrm{~A} \mathrm{~m}^{2} / \mathrm{kg}\right)$ & $0.285^{*}$ & $0.632^{* *}$ & 0.021 & $0.449^{*}$ & $0.437^{*}$ \\
\hline SOFT $\left(10^{-5} \mathrm{~A} \mathrm{~m}^{2} / \mathrm{kg}\right)$ & $0.337^{*}$ & $0.629^{* *}$ & 0.178 & $0.449^{*}$ & $0.437^{*}$ \\
\hline $\operatorname{HIRM}\left(10^{-5} \mathrm{~A} \mathrm{~m}^{2} / \mathrm{kg}\right)$ & 0.055 & 0.130 & 0.040 & $0.411^{*}$ & $0.436^{*}$ \\
\hline
\end{tabular}

Note: ${ }^{*}$ and ${ }^{* *}$ mean significance at the 0.05 level and 0.01 level (two-sided test), respectively. 


\section{Conclusions}

The magnetic minerals in the surface soil in Shihezi city were dominated by magnetite or MD ferromagnetic minerals, accompanied by a small amount of canted anti-ferromagnetic minerals. There were some similarities in the spatial distributions of $\chi_{\mathrm{LF}}, \chi_{\mathrm{ARM}}$, SIRM and SOFT, with the relatively higher values on both sides of the roads. In terms of the four sub-regions, the content of soil ferromagnetic minerals was found to be highest in N-B, followed by U, F, and then N-A. Due to sulfide pollutants from heavy chemical industry, the concentration of soil magnetic minerals in N-A was abnormally low. The spatial differences in soil magnetic parameters reflected the pollution status of soil, as the magnetic environment was influenced by human activities with different functional areas, timespans and intensities.

The average organic matter content in surface soil of Shihezi was $34.69 \mathrm{~g} / \mathrm{kg}$, with great differences existed in the four sub-regions. In N-A and N-B, grasslands existed prior to the urban development, and thus soil organic matter contents were relatively higher in $\mathrm{N}-\mathrm{A}$ and N-B (48.8 and $50.3 \mathrm{~g} / \mathrm{kg}$, respectively) than those in $\mathrm{U}$ and $\mathrm{F}$ (26.7 and $29.5 \mathrm{~g} / \mathrm{kg}$, respectively). The soil in the study area is slight alkaline, with an average $\mathrm{pH}$ of 7.93. Soil $\mathrm{pH}$ in $\mathrm{U}$ was found to be the highest among the four sub-regions, and there was no significant correlation between soil $\mathrm{pH}$ and magnetic parameters in the soil samples.

Significant correlation was found between soil organic matter contents and magnetic parameters (except for $\chi_{\mathrm{FD}}$ ) in the surface soils of N-A and N-B. In F, soil organic matter content was significantly negatively correlated with $\chi_{\mathrm{LF}}$, but not significantly correlated with other magnetic parameters (i.e. $\chi_{\mathrm{ARM}}, \mathrm{SIRM}$, SOFT, $\chi_{\mathrm{FD}}$ and HIRM). The correlation analysis in $\mathrm{U}$ suggested the same situation as found in N-A and N-B except for HIRM. The correlation between soil organic matter content and magnetic parameters in $\mathrm{U}, \mathrm{N}-\mathrm{A}$ and N-B was greater than that in F. These results showed that, in built-up areas of Shihezi, there were significant correlations of soil organic matter contents with ferromagnetic mineral particles and low coercive MD ferromagnetic mineral particles, but there was no correlation between soil organic matter contents and high coercive canted anti-ferromagnetic minerals (hematite and goethite). Meanwhile, in the new northern urban areas (N-A and N-B), soil organic matter contents were significantly correlated with ferromagnetic mineral particles, low coercive MD ferromagnetic mineral particles and high coercive canted anti-ferromagnetic minerals (hematite and goethite).

\section{Acknowledgements}

This study was funded by the National Natural Science Foundation of China (41171165, 41161029), the Importation and Development of High-Caliber Talents Project of Beijing Municipal Institutions (IDHT20130322) and the Talent Strong School Plan of Funded Project of Beijing Union University (BPHR2012E01).

\section{References}

Burgess E W. 2008. The growth of the city: an introduction to a research project. In: Marzluff J M, Shulenberger E, Endlicher W, et al. Urban Ecology. Washington: Springer US, 71-78.

Chabukdhara M, Nema A K. 2013. Heavy metals assessment in urban soil around industrial clusters in Ghaziabad, India: probabilistic health risk approach. Ecotoxicology and Environmental Safety, 87: 57-64.

Chen X L, Li Z Z, Jin J H, et al. 2011. Soil pH value, organic matter and magnetic susceptibility in different urban function zones of Fuzhou City. Bulletin of Soil and Water Conservation, 31: 176-181. (in Chinese)

Davis J A. 1984. Complexation of trace metals by adsorbed natural organic matter. Geochimica et Cosmochimica Acta, 48(4): 679-691.

Day R, Fuller M, Schmidt V A. 1977. Hysteresis properties of titanomagnetites: grain-size and compositional dependence. Physics of the Earth and Planetary Interiors, 13(4): 260-267.

De Kimpe C R, Morel J L. 2000. Urban soil management: a growing concern. Soil Science, 165(1): 31-40.

Dearing J A, Dann R J L, Hay K, et al. 1996. Frequency-dependent susceptibility measurements of environmental materials. Geophysical Journal International, 124(1): 228-240.

Dearing J A, Bird P M, Dann R J L, et al. 1997. Secondary ferrimagnetic minerals in Welsh soils: a comparison of mineral magnetic detection methods and implications for mineral formation. Geophysical Journal International, 130(3): 727-736.

Durža O. 1999. Heavy metals contamination and magnetic susceptibility in soils around metallurgical plant. Physics and Chemistry of the Earth, Part A: Solid Earth and Geodesy, 24(6): 541-543.

Elliott R J R, Sun P, Zhu T. 2014. Urbanization and energy intensity: a province-level study for China. Department of Economics Discussion Paper 14-05. University of Birmingham, Birmingham, UK.

Elmqvist T, Fragkias M, Goodness J, et al. 2013. Stewardship of the biosphere in the urban era. In: Elmqvist T, Fragkias M, Goodness J, et al. Urbanization, Biodiversity and Ecosystem Services: Challenges and Opportunities. Berlin: Springer Netherlands, 719-746.

Evans M, Heller F. 2003. Environmental Magnetism: Principles and 
Applications of Enviromagnetics. Oxford: Academic Press, 573.

Gautam P, Blaha U, Appel E. 2005. Integration of magnetism and heavy metal chemistry of soils to quantify the environmental pollution in Kathmandu, Nepal. Island Arc, 14(4): 424-435.

Huang Y L, Wang Y L, Zhang L P. 2008. Long-term trend of chemical composition of wet atmospheric precipitation during 1986-2006 at Shenzhen City, China. Atmospheric Environment, 42(16): 3740-3750.

Jing Y J, Zheng D M, Lu S Q, et al. 2004. The composition features and content of organic matter in the cropland soils of Xinjiang. Agricultural Research in Arid Areas, 21: 61-64. (in Chinese)

Jorgenson A K, Rice J. 2005. Structural dynamics of international trade and material consumption: A cross-national study of the ecological footprints of less-developed countries. Journal of World-Systems Research, 11(1): 57-77.

Kapička A, Petrovský E, Ustjak S, et al. 1999. Proxy mapping of fly-ash pollution of soils around a coal-burning power plant: a case study in the Czech Republic. Journal of Geochemical Exploration, 66(1): 291-297.

Kapička A, Jordanova N, Petrovský E, et al. 2000. Magnetic stability of power-plant fly ash in different soil solutions. Physics and Chemistry of the Earth, Part A: Solid Earth and Geodesy, 25(5): 431-436.

Kong S F, Ji Y Q, Liu L L, et al. 2012. Diversities of phthalate esters in suburban agricultural soils and wasteland soil appeared with urbanization in China. Environmental Pollution, 170: 161-168.

Li X Y, Liu L J, Wang Y G, et al. 2013. Heavy metal contamination of urban soil in an old industrial city (Shenyang) in Northeast China. Geoderma, 192: 50-58.

Lourenço A M, Rocha F, Gomes C R. 2012. Relationships between magnetic parameters, chemical composition and clay minerals of topsoils near Coimbra, central Portugal. Natural Hazards and Earth System Science, 12(8): 2545-2555.

Maher B A. 1998. Magnetic properties of modern soils and Quaternary loessic paleosols: paleoclimatic implications. Palaeogeography, Palaeoclimatology, Palaeoecology, 137(1): 25-54.

Murdock K J, Wilkie K, Brown L L. 2013. Rock magnetic properties, magnetic susceptibility, and organic geochemistry comparison in core LZ1029-7 Lake El'gygytgyn, Russia Far East. Climate of the Past, 9(1): 467-479.

Oldfield F. 1991. Environmental magnetism - a personal perspective. Quaternary Science Reviews, 10(1): 73-85.

Reuter J H, Perdue E M. 1977. Importance of heavy metal-organic matter interactions in natural waters. Geochimica et Cosmochimica Acta, 41(2): 325-334.

Rosowiecka O, Nawrocki J. 2010. Assessment of soils pollution extent in surroundings of ironworks based on magnetic analysis. Studia
Geophysica et Geodaetica, 54(1): 185-194.

Shen H Y, Chen J L, Dai H F, et al. 2013. New insights into the sorption and detoxification of chromium (VI) by tetraethylenepentamine functionalized nanosized magnetic polymer adsorbents: mechanism and $\mathrm{pH}$ effect. Industrial \& Engineering Chemistry Research, 52(36): 12723-12732.

Si P, Zheng Z F, Ren Y, et al. 2014. Effects of urbanization on daily temperature extremes in North China. Journal of Geographical Sciences, 24(2): 249-268.

Thompson R, Oldfield F. 1986. Environmental Magnetism. London: Allen \& Unwin, 277.

Tu J, Wang H S, Zhang Z F, et al. 2005. Trends in chemical composition of precipitation in Nanjing, China, during 1992-2003. Atmospheric Research, 73(3-4): 283-298.

Wang B, Xia D S, Yu Y, et al. 2013. Magnetic properties of river sediments and their relationship with heavy metals and organic matter in the urban area in Lanzhou, China. Environmental Earth Sciences, 70(2): 605-614.

Wang B, Xia D, Yu Y, et al. 2014. Detection and differentiation of pollution in urban surface soils using magnetic properties in arid and semi-arid regions of northwestern China. Environmental Pollution, 184: 335-346.

Wang X S. 2013. Assessment of heavy metal pollution in Xuzhou urban topsoils by magnetic susceptibility measurements. Journal of Applied Geophysics, 92: 76-83.

Wei B G, Yang L S. 2010. A review of heavy metal contaminations in urban soils, urban road dusts and agricultural soils from China. Microchemical Journal, 94(2): 99-107.

Xia D S, Wang B, Yu Y, et al. 2014. Combination of magnetic parameters and heavy metals to discriminate soil-contamination sources in Yinchuan-A typical oasis city of Northwestern China. Science of The Total Environment, 485: 83-92.

Yang H, Xiong H G, Chen X G. 2014. Environmental magnetic propertires and their spatial variability of topsoil in Shihezi city. Environmental Science, 35: 3537-3545. (in Chinese)

Yang Z P, Lu W X, Long Y Q, et al. 2011. Assessment of heavy metals contamination in urban topsoil from Changchun City, China. Journal of Geochemical Exploration, 108(1): 27-38.

Zeng F R, Ali S, Zhang H T, et al. 2011. The influence of $\mathrm{pH}$ and organic matter content in paddy soil on heavy metal availability and their uptake by rice plants. Environmental Pollution, 159(1): 84-91.

Zheng Y, Zhang S H. 2008. Magnetic properties of street dust and topsoil in Beijing and its environmental implications. Chinese Science Bulletin, 53(3): 408-417. 